\title{
COMMENTARY
}

\section{Norepinephrine: more of a neurohormone than a vasopressor}

\author{
John Myburgh $h^{1,2,3 *}$ \\ See related research by Hamzaoui et al., http://ccforum.com/content/14/4/R142
}

\begin{abstract}
Septic shock causes unpredictable cardiovascular responses through adrenoreceptor-mediated changes in cardiac function and vascular responsiveness.

The use of norepinephrine should be regarded as neurohormonal augmentation therapy to defend decompensating haemodynamic function rather than as a rescue therapy to treat shock. Recent trials represent a perceptible change in clinical practice to preferentially use norepinephrine early in resuscitation to defend the mean arterial pressure and to use norepinephrine as a neurohormone rather than as a vasopressor.
\end{abstract}

In the previous issue of Critical Care, Hamzaoui and colleagues present an observational study on the haemodynamic effects of norepinephrine in septic patients with life-threatening hypotension [1]. Within 6 hours of admission to the intensive care unit, a threshold mean arterial pressure (MAP) $\leq 65 \mathrm{mmHg}$ was selected to commence an infusion of norepinephrine, regardless of the degree of prior volume resuscitation. Measurements of cardiac index and derived indices of preload (enddiastolic global volume index) and stroke volume variation were made at baseline and following augmentation of MAP with norepinephrine. The patients were further categorised according to baseline left ventricular ejection fraction and whether they were able to achieve the target MAP. The investigators found that norepinephrine significantly increased MAP to a median value of $75 \mathrm{mmHg}$, which was associated with significant increases in cardiac output and indices of stroke volume and preload. This effect was consistent independent of

*Correspondence: jmyburgh@georgeinstitute.org.au

'Division of Critical Care and Trauma, The George Institute for Global Health,

Level 7, 341 George Street, Sydney, Australia

Full list of author information is available at the end of the article baseline left ventricular ejection fraction - apart from those patients with left ventricular ejection fraction $<45 \%$, who attained MAP $>75 \mathrm{mmHg}$. The authors concluded that the early administration of norepinephrine directed at achieving a target systemic perfusion pressure was achievable through parallel increases in cardiac output and preload.

Although Hamzaoui and colleagues' study is observational and single-centred in a relatively small population of septic patients using derived indices from pulse contour analysis to quantify changes in preload and contractility [1], the results are consistent with physiological models that define the protean haemodynamic effects of endogenous catecholamines, specifically norepinephrine, under homeostatic and pathological conditions.

Norepinephrine is the predominant endogenous sympathetic amine acting in all populations of adrenoreceptors [2]. There is a common misperception that this amine is predominantly an $\alpha$-agonist. Norepinephrine exhibits sympathetic activity over an expanding population of adrenoreceptors on the circulation $\left(\alpha_{1 \mathrm{~A}}\right.$ and $\alpha_{1 \mathrm{~B}}$, $\alpha_{2 \mathrm{~A}}, \alpha_{2 \mathrm{~B}}$ and $\alpha_{2 \mathrm{C}}, \beta_{1}, \beta_{2}$ and $\beta_{3}$ ), acting centrally on the myocardium, on the arterial (conduit) circulation and on the venous (capacitance) circulation [3]. Haemodynamic function at any point in time represents the balance between the two circulations, so that changes in one are represented by compensatory changes in the other $[4,5]$.

Under pathological conditions such as septic shock, qualitative and quantitative changes in cardiac function and vascular responsiveness result in unpredictable cardiovascular responses between and within individuals, initially as a compensated high output or vasodilated state to a decompensated low output or vasoplegic state. Teleologically, this represents exhaustion of endogenous neurohumoral responses induced by pathological processes or an overwhelmed host response. In this context, the use of exogenous infusions of catecholamines, such as norepinephrine or epinephrine, should be seen as neurohormonal augmentation therapy to defend decompensating haemodynamic function rather than as a rescue therapy to treat shock [6]. 
This understanding is somewhat at variance to traditional clinical practice, supported by current guidelines that recommend haemodynamic resuscitation follows a step-wise approach - initial fluid loading, followed by the use of an inotrope to improve cardiac output, followed by a vasopressor to squeeze the circulation to augment the perfusion pressure [7].

Three recently published randomised controlled trials comparing the effects of catecholamines in severe sepsis have demonstrated equivalence in haemodynamic responses without adverse effects on organ function or mortality [8-10]. Of the three catecholamines studied, norepinephrine was associated with the lowest incidence of drug-specific side effects compared with epinephrine (hyperlactataemia and hyperglycaemia) and dopamine (arrhythmias). On the basis of these studies and a recent commentary [11], norepinephrine appears to be the initial agent of choice. Furthermore, these trials represent a perceptible change in clinical practice to preferentially use catecholamines early in resuscitation to defend MAP as the principal haemodynamic endpoint, although it is acknowledged that there is little evidence or agreement on an optimal perfusion pressure in septic shock [12].

The justification for selecting MAP is based on pragmatic reasons - MAP is easy and accurate to measure as well as it being an aggregate index of organ perfusion pressure. However, as there is little direct relationship between perfusion pressure and venous return, which remains difficult to measure under clinical conditions, clinicians rely on the assumption that parallel changes in the arterial and venous circulations will occur.

The use of norepinephrine as a neurohormonal augmentation therapy by Hamzaoui and colleagues demonstrated inotropic and vasopressor responses in a heterogeneous population of patients with severe sepsis using current monitoring techniques [1]. These data are consistent with established biological and basic science evidence, and provide additional strength to the argument for viewing norepinephrine as a neurohormone rather than as a vasopressor and to recommend its early use as the first-line agent for life-threatening hypotension.

Abbreviations

MAP, mean arterial pressure.
Competing interests

The author declares that he has no competing interests.

\section{Author details}

'Division of Critical Care and Trauma, The George Institute for Global Health, Level 7, 341 George Street, Sydney 2000, Australia. ${ }^{2}$ Department of Critical Care Medicine, University of New South Wales, Sydney, 2052, Australia. ${ }^{3}$ Department of Intensive Care Medicine, St George Hospital, Gray Street, Kogarah, Sydney 2217, Australia.

Published: 20 September 2010

\section{References}

1. Hamzaoui O, Georger J-F, Monnet X, Ksouri H, Maizel J, Richard C, Teboul J-L: Early administration of norepinephrine increases cardiac preload and cardiac output in septic patients with life-threatening hypotension. Crit Care 2010, 14:R142

2. Insel PA: Seminars in medicine of the Beth Israel Hospital, Boston Adrenergic receptors-evolving concepts and clinical implications. N Engl J Med 1996, 334:580-585

3. Hein L: Adrenoceptors and signal transduction in neurons. Cell Tissue Res 2006, 326:541-551.

4. Bressack MA, Raffin TA: Importance of venous return, venous resistance, and mean circulatory pressure in the physiology and management of shock. Chest 1987, 92:906-912.

5. Jacobsohn $\mathrm{E}$, Chorn $\mathrm{R}, \mathrm{O}^{\prime}$ Connor M: The role of the vasculature in regulating venous return and cardiac output: historical and graphical approach. Can J Anaesth 1997, 44:849-867

6. Myburgh JA: An appraisal of selection and use of catecholamines in septic shock - old becomes new again. Crit Care Resusc 2006, 8:353-360

7. Dellinger RP, Levy MM, Carlet JM, Bion J, Parker MM, Jaeschke R, Reinhart K, Angus DC, Brun-Buisson C, Beale R, Calandra T, Dhainaut JF, Gerlach H, Harvey M, Marini JJ, Marshall J, Ranieri M, Ramsay G, Sevransky J, Thompson BT, Townsend S, Vender JS, Zimmerman JL, Vincent JL: Surviving Sepsis Campaign: international guidelines for management of severe sepsis and septic shock: 2008. Crit Care Med 2008, 36:296-327.

8. Annane D, Vignon P, Renault A, Bollaert PE, Charpentier C, Martin C, Troche G, Ricard JD, Nitenberg G, Papazian L, Azoulay E, Bellissant E: Norepinephrine plus dobutamine versus epinephrine alone for management of septic shock: a randomised trial. Lancet 2007, 370:676-684.

9. Myburgh JA, Higgins A, Jovanovska A, Lipman J, Ramakrishnan N, Santamaria $\mathrm{J}$ : A comparison of epinephrine and norepinephrine in critically ill patients. Intensive Care Med 2008, 34:2226-2234.

10. De Backer D, Biston P, Devriendt J, Madl C, Chochrad D, Aldecoa C, Brasseur A, Defrance $P$, Gottignies $P$, Vincent JL: Comparison of dopamine and norepinephrine in the treatment of shock. N Engl J Med 2010, 362:779-789.

11. Maybauer MO, Walley KR: Best vasopressor for advanced vasodilatory shock: should vasopressin be part of the mix? Intensive Care Med 2010, 36:1484-1487.

12. Shapiro DS, Loiacono LA: Mean arterial pressure: therapeutic goals and pharmacologic support. Crit Care Clin 2010, 26:285-293, table.

doi:10.1186/cc9246

Cite this article as: Myburgh J: Norepinephrine: more of a neurohormone than a vasopressor. Critical Care 2010, 14:196. 